\title{
Analisis Statistical Process Control dalam Pengujian Kestabilan Alat Pengukur Kadar Glukosa Darah Non-Invasif
}

\author{
Renaldy Dermawan*, Erfiani*, Akbar Rizki* \\ ${ }^{*}$ Departemen Statistika Institut Pertanian Bogor
}

\begin{abstract}
Abstrak-Kestabilan pada suatu alat pengukuran adalah sangat penting. Hal ini diperlukan untuk mendapatkan hasil pengukuran yang memiliki presisi tinggi. Penelitian ini dilakukan untuk melihat kestabilan pada alat pengukur kadar glukosa darah non-invasif. Data penelitian ini merupakan bagian dari data penelitian "Pengembangan dan Uji Klinis Purwarupa Alat Pemantauan Kadar Glukosa Darah Non-Invasif Institut Pertanian Bogor". Analisis yang digunakan adalah statistical process control menggunakan bagan kendali mutu Individual Moving Range. Hasil yang diperoleh mengindikasikan kestabilan proses pada masing-masing responden. Namun demikian, antar responden yang satu dengan responden yang lainnya memiliki proses yang belum stabil meskipun kadar glukosa darah yang dimiliki oleh responden tersebut sama.

Kata kunci-bagan kendali mutu Individual Moving Range; glukosa darah; kestabilan alat; statistical process control;
\end{abstract}

\section{PENDAHULUAN}

\section{A. Latar Belakang}

Maslow (1984) menyatakan bahwa kesehatan merupakan salah satu aspek terpenting dalam kehidupan manusia. Gangguan kesehatan dapat berpengaruh terhadap seluruh kegiatan manusia. Munculnya gangguan kesehatan yang berkaitan dengan metabolisme kadar glukosa darah salah satunya yaitu gangguan glikemik. Gangguan glikemik merupakan salah satu masalah kesehatan yang sering muncul, salah satu contohnya adalah diabetes. Menurut World Health Organization (WHO), penderita diabetes di dunia diperkirakan akan berjumlah 366 juta orang pada tahun 2030. Hal tersebut merupakan peningkatan jumlah penderita diabetes yang awalnya sebanyak 171 juta orang pada tahun 2000. Indonesia menempati posisi ke-4 di dunia teratas dengan jumlah penderita diabetes terbanyak setelah India, China, dan Amerika Serikat (Wild et al. (2004)). ADA (2014) atau American Diabetes Association menjelaskan bahwa diabetes diawali oleh keadaan hiperglikemia. Hiperglikemia ditunjukkan oleh kadar glukosa darah yang melebihi kadar normal. Kondisi hiperglikemia yang kronis dan tidak terkontrol akan menyebabkan seseorang dapat jatuh pada keadaan diabetes.

Menurut ADA (2014) atau American Diabetes Association, pendeteksian kadar glukosa darah untuk masalah diabetes sangat penting dilakukan sejak dini. Selain sebagai pencegahan bagi yang belum menderita, pemeriksaan secara rutin berguna untuk kontrol secara berkala bagi yang sudah menderita. Teknik pendeteksian kadar glukosa darah dapat dilakukan secara invasif maupun non-invasif. Pendeteksian kadar glukosa darah secara invasif menimbulkan ketidaknyamanan karena dilakukan dengan melukai tubuh. Oleh sebab itu, dikembangkanlah pendeteksian kadar glukosa darah tanpa melukai tubuh (non-invasif).

Alat pengukur kadar glukosa darah non-invasif menggunakan prinsip spektroskopi inframerah. Cara kerja alat ini adalah menyinari jari tangan dengan lampu inframerah, sebagian intensitas inframerah akan diserap dan sebagian lain dilewatkan. Intensitas yang terlewat ini selanjutnya ditangkap oleh sensor dalam bentuk tegangan analog. Tegangan ini selanjutnya dikonversi menjadi tegangan digital melalui komponen Analog Digital Converter. Tegangan digital yang dihasilkan selanjutnya ditransformasi menggunakan algoritma Fast Fourier Transform. Hasil transformasi ini ditampilkan dalam bentuk spektrum time domain terhadap frekuensi.

Alat pengukur kadar glukosa darah non-invasif yang akan digunakan untuk mendeteksi kadar glukosa darah pada masalah diabetes perlu diuji 
kestabilannya. Proses menangkap residu intensitas pada alat harus menunjukan proses yang stabil atau terkendali. Hal ini menunjukan bahwa keragaman residu intensitas menjadi minimum dan memiliki presisi yang tinggi atau dengan kata lain alat pengukur kadar glukosa darah non-invasif sudah stabil.

\section{B. Tujuan}

Tujuan penelitian ini untuk melihat kestabilan alat pengukur kadar glukosa darah non-invasif berdasarkan spektrum residu intensitas terhadap modulasi hasil keluaran alat pengukur kadar glukosa darah non-invasif

\section{TINJAUAN PUSTAKA}

\section{A. Kadar Glukosa Darah}

Menurut ADA (2014) atau American Diabetes Association, tingkat kadar glukosa darah seseorang dipengaruhi oleh konsumsi karbohidrat, aktivitas fisik, waktu tidur, psikologis, kualitas dan kuantitas hormon insulin, penggunaan obat, stress, siklus mentruasi, dehidrasi, dan konsumsi alkohol. Kadar glukosa dalam darah dinyatakan dalam satuan miligram per desiliter (mg/dL). Kadar glukosa dalam darah yang umumnya terjadi pada manusia dijelaskan oleh Tabel I.

\section{Tabel I}

KRITERIA DIABETES BERDASARKAN AMERICAN DiABETES ASSOCIATION

\begin{tabular}{cccc}
\hline $\begin{array}{c}\text { Pemeriksaaan Kadar } \\
\text { Glukosa Darah }\end{array}$ & $\begin{array}{c}\text { Normal } \\
(\mathrm{mg} / \mathrm{dL})\end{array}$ & $\begin{array}{c}\text { Pra Diabetes } \\
(\mathrm{mg} / \mathrm{dL})\end{array}$ & $\begin{array}{c}\text { Diabetes } \\
(\mathrm{mg} / \mathrm{dL})\end{array}$ \\
\hline Sewaktu & $140-199$ & & $\geq 200$ \\
Puasa & $<108$ & $108-125$ & $\geq 126$ \\
Dua Jam Setelah Makan & $<140$ & $140-199$ & $\geq 200$ \\
\hline
\end{tabular}

\section{B. Pengukuran Kadar Glukosa Darah}

Menurut Stuart (2004), alat pengukur kadar glukosa darah non-invasif menggunakan prinsip spektroskopi inframerah. Cara kerja alat ini adalah menyinari jari tangan dengan lampu inframerah. Sebagian intensitas inframerah akan diserap oleh bagian tubuh yang disiniari dan sebagian lain akan dilewatkan. Intensitas yang terlewat ini selanjutnya ditangkap oleh sensor. Setelah itu, residu intensintas yang ditangkap oleh sensor akan dikeluarankan berapa spektrum residu intensitas terhadap modulasi akan ditampilkan pada layar Liquid Crystal Display (LCD).

\section{Bagan Kendali Mutu Individual Moving Range}

Menurut Montgomerry (2009), bagan kendali mutu Individu-Moving Range merupakan bagan kendali dengan menggunakan ukuran contoh $\mathrm{n}=1$. Beberapa kondisi dalam proses pengendalian adalah menggunakan teknologi otomatis dalam inspeksi atau pengukuran dan setiap unit yang dihasilkan akan dianalisis sehingga tidak ada dasar untuk subgrouping. Jika bagan kendali mutu Individual Moving Range keduanya menunjukkan amatan yang tidak terkendali maka harus dilakukan terlebih dahulu pencarian terhadap penyebab dari amatanamatan yang tidak terkendali pada bagan Moving Range. Setelah itu, sebab-sebab terduga pada bagan Moving Range akan dihilangkan. Interpretasi pada bagan Individual tidak dilakukan jika bagan Moving Range tidak terkendali.

Bagan kendali mutu Moving Range digunakan untuk mengendalikan ukuran penyebaran sedangkan bagan kendali mutu Individual digunakan untuk mengendalikan ukuran pemusatan. Perhitngan nilai Moving Range merupakan perhitungan iteratif. Keragaman proses didefinisikan menggunakan dua observasi berurutan. Batas bagan kendali Moving Range yaitu:

$$
\begin{gathered}
B P A=\overline{M R}+3 d 3 \frac{\overline{M R}}{d 2} \\
B P=\overline{M R} \\
B P B=\overline{M R}-3 d 3 \frac{\overline{M R}}{d 2}
\end{gathered}
$$

Bagan kendali mutu Individual adalah bagan kendali untuk mengendalikan ukuran pemusatan. Batas bagan kendali Individual yaitu:

$$
\begin{gathered}
B P A=\bar{X}+3 d 3 \frac{\overline{M R}}{d 2} \\
B P=\bar{X} \\
B P B=\bar{X}-3 d 3 \frac{\overline{M R}}{d 2}
\end{gathered}
$$

Keterangan:

BPA : Batas Pengendali Atas

BP : Batas Pengendali 
BPB : Batas Pengendali Bawah

$\bar{X}$ : Nilai rata-rata

$\overline{M R}$ : Nilai rata-rata moving range

d2 : Nilai yang didapat dari tabel

d3 : Nilai yang didapat dari tabel

Penelitian ini menggunakan Nelson Rules sebagai aturan sensitifitas, keterkendalian, dan kestabilan. Aturan yang dimaksud yakni

1) satu poin yang lebih besar dibandingkan tiga standar deviasi dari CL

2) sembilan poin berada pada sisi yang sama dari $\mathrm{CL}$

3) enam poin dalam satu baris membentuk pola menaik atau menurun

4) delapan poin dalam satu baris lebih besar dibandingkan satu standar deviasi dari CL

5) dua dari tiga poin secara beurutan lebih besar dibandingkan dua standar deviasi dari CL

6) empat dari lima poin berurutan lebih besar dibandingkan satu standar deviasi dari CL

7) 14 poin dalam satu baris secara alternatif menaik dan menurun

8) 15 poin dalam satu baris dengan nilai satu standar deviasi dari CL

\section{METODE}

\section{A. Data}

Data yang digunakan dalam penelitian ini adalah data primer. Data primer tersebut merupakan bagian dari data penelitian "Pengembangan dan Uji Klinis Purwarupa Alat Pemantauan Kadar Glukosa Darah Non-Invasif Institut Pertanian Bogor". Penelitian ini dilaksanakan pada April 2016 - Januari 2017. Penelitian ini didanai oleh Program Insentif Riset Sistem Inovasi Nasional, Kementerian Riset Teknologi dan Pendidikan Tinggi. Penelitian ini menggunakan 118 responden sukarela yang merupakan mahasiswa dari beberapa departemen di Institut Pertanian Bogor Pengambilan data dilakukan di Laboratorium Biokimia, Departemen Gizi Masyarakat Institut Pertanian Bogor.

Penelitian ini menggunakan satu alat pengukur kadar glukosa darah non-invasif yang akan diuji kestabilannya. Data yang diperoleh dari alat tersebut berupa data spektrum residu intensitas terhadap modulasi lima kali ulangan setiap responden. Lima kali ulangan tersebut sebelumnya sudah diatur oleh operator sehingga alat non-invasif dapat melakukan ulangan tersebut secara otomatis. Kondisi yang digunakan pada penelitian ini adalah ketika hanya salah satu lampu yang hidup yaitu lampu inframerah $1600 \mathrm{~nm}$.

Kondisi yang digunakan pada penelitian tersebut memiliki sepuluh modulasi. Modulasi merupakan seberapa besarnya intensintas cahaya yang dipancarkan oleh lampu inframerah. Modulasi berkisar dari nilai $0 \%$ sampai $90 \%$ dengan jarak $10 \%$. Setiap modulasi memiliki dua puncak dan satu lembah. Puncak tersebut mengartikan bahwa lampu tersebut hidup sedangkan lembah mengartikan bahwa lampu tersebut mati. Proses bergantinya kondisi tersebut berlangsung dengan cepat. Oleh sebab itu, kondisi yang teramati hanya seperti terang dan redup tergantung dari berapa persen modulasinya. Penelitian ini hanya menggunakan data dari dua puncak tersebut dan tidak menggunakan data lembah.

\section{B. Prosedur Analisis Data}

Tahapan analisis data pada penelitian ini adalah sebagai berikut :

1) Melakukan eksplorasi pada data kadar glukosa darah invasif hasil pengukuran laboratorium dengan melihat plot dari seluruh responden terhadap kadar glukosa darah invasif.

2) Melakukan pemilihan responden yang akan digunakan untuk analisis. Pemilihan responden dilakukan secara acak.

3) Melakukan eksplorasi spektrum hasil keluaran alat non-invasif pada responden yang terpilih berdasarkan kategori diabetes.

4) Melakukan pemangkasan data puncak spektrum pada spektrum hasil keluaran alat non-invasif pada responden yang terpilih berdasarkan kategori diabetes.

5) Mencari modulasi terbaik.

6) Membuat bagan kendali Individual Moving Range menggunakan modulasi terbaik tersebut. Selain itu, dilakukan evaluasi terhadap hasil dari bagan kendali tersebut. 


\section{HASIL DAN PEMBAHASAN}

\section{A. Eksplorasi Data}

Eksplorasi data kadar glukosa darah invasif hasil pengukuran laboratorium dilakukan dengan melihat plot dan diagram batang dari data kadar glukosa darah invasif pada 118 responden. Tujuan dari pembuatan plot dan diagram untuk melihat pola data kadar glukosa invasif dari 118 responden dan menentukan responden yang akan dilakukan metode statistical process control (bagan kendali mutu). Gambar 1 merupakan plot kadar glukosa darah invasif yang menunjukan bahwa kadar glukosa darah invasif hasil pengukuran laboratorium memiliki pola yang cenderung konstan. Data kadar glukosa darah invasif tersebut memiliki pola yang cenderung konstan di kadar glukosa darah sekitar $80 \mathrm{mg} / \mathrm{dL}$. Data kadar glukosa darah invasif memiliki rata-rata 82.64 $\mathrm{mg} / \mathrm{dL}$, median $80 \mathrm{mg} / \mathrm{dL}$, dan kadar glukosa terkecil $67 \mathrm{mg} / \mathrm{dL}$. Selain itu, terdapat satu responden yang memiliki kadar glukosa darah yang sangat tinggi dibandingkan dengan responden lainnya yaitu kadar glukosa sebesar 276 mg/dL.

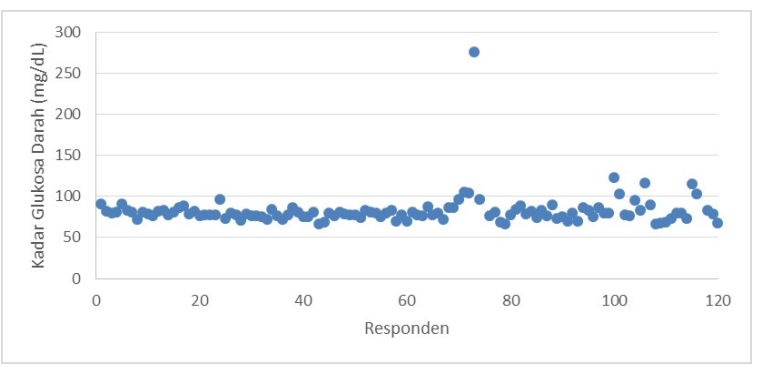

Gambar 1. Plot kadar glukosa darah invasif

Gambar 2 menunjukan bahwa sebanyak 114 responden masuk dalam kategori normal, 3 responden masuk dalam kategori pra diabetes, dan 1 responden masuk dalam kategori diabetes. Penelitian ini mengambil satu responden yang mewakili kategori diabetes. Berdasarkan hasil pengacakan didapat tiga responden yang memiliki kadar glukosa darah dengan masing-masing kadar glukosa darah yaitu 67 $\mathrm{mg} / \mathrm{dL}, 123 \mathrm{mg} / \mathrm{dL}$, dan $276 \mathrm{mg} / \mathrm{dL}$. Analisis statistical process control (bagan kendali mutu) akan menggunakan tiga responden tersebut. Penelitian ini juga menggunakan beberapa kadar glukosa darah lainnya berdasarkan pertimbangan jumlah responden yang memiliki kadar glukosa darah tersebut.
Kadar glukosa darah yang dimaksud yaitu $68 \mathrm{mg} / \mathrm{dL}$ sebanyak dua responden, $87 \mathrm{mg} / \mathrm{dL}$ sebanyak tiga responden, $70 \mathrm{mg} / \mathrm{dL}$ sebanyak empat responden, dan $76 \mathrm{mg} / \mathrm{dL}$ sebanyak lima responden.

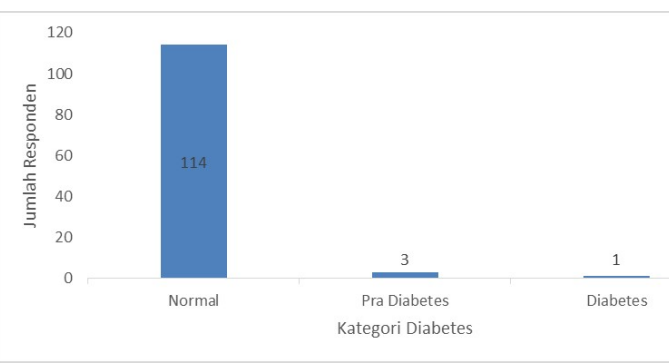

Gambar 2. Diagram batang kategori diabetes

Plot hasil pengukuran kadar glukosa darah 67 $\mathrm{mg} / \mathrm{dL}, 123 \mathrm{mg} / \mathrm{dL}$, dan $276 \mathrm{mg} / \mathrm{dL}$ menggunakan alat non-invasif masing-masing ditunjukan oleh Gambar 3, Gambar 4, dan Gambar 5. Hasil pengukuran digambarkan oleh spektrum residu intensitas terhadap data pengambilan. Terdapat lima spektrum yang berasal dari hasil pengukuran kadar glukosa non-invasif dengan satu jari tangan dari satu responden untuk lima kali ulangan. Lima kali ulangan tersebut sebelumnya sudah diatur oleh operator sehingga alat non-invasif dapat melakukan ulangan tersebut secara otomatis. Secara keseluruhan pola spektrum untuk setiap ulangan pada masing-masing kadar glukosa darah cenderung sama.

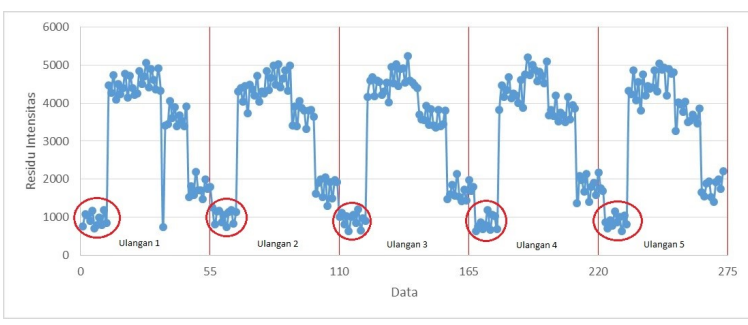

Gambar 3. Spektrum gabungan kadar glukosa darah $67 \mathrm{mg} / \mathrm{dL}$ dari hasil keluaran alat non-invasif 


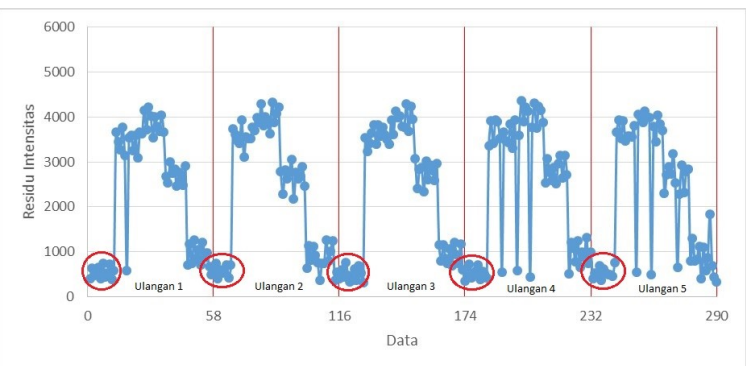

Gambar 4. Spektrum gabungan kadar glukosa darah $123 \mathrm{mg} / \mathrm{dL}$ dari hasil keluaran alat non-invasif

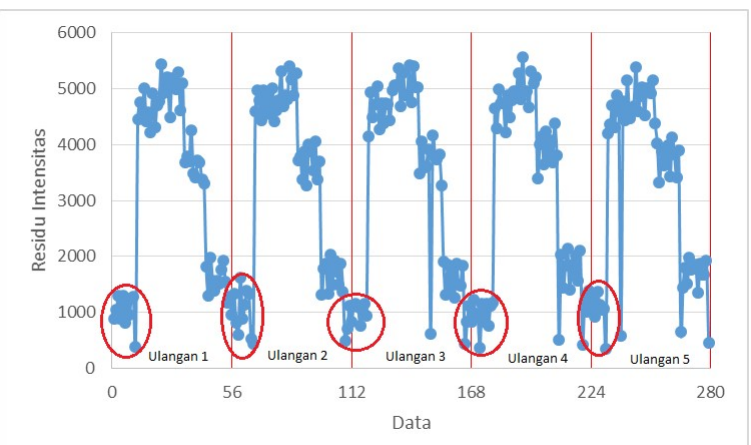

Gambar 5. Spektrum gabungan kadar glukosa darah 276 mg/dL dari hasil keluaran alat non-invasif

\section{B. Modulasi Terbaik}

Modulasi terbaik ditunjukan ketika suatu modulasi memiliki intensitas yang konsisten, konstan, dan terendah. Konsisten yang dimaksud adalah modulasi tersebut memiliki ragam residu intensitas terkecil dibandingkan dengan modulasi lainnya di dalam ulangan yang sama. Setelah didapatkan modulasi yang konsisten, modulasi tersebut diharapkan memiliki residu intensitas yang konstan. Konstan yang dimaksud adalah modulasi tersebut memiliki nilai tengah yang cenderung sama pada setiap ulangannya. Selain konsisten dan konstan, modulasi terbaik sebaiknya memiliki tingkat residu intensitas yang rendah dibandingkan modulasi lainnya.

Modulasi 50\% merupakan modulasi yang memiliki tingkat kekonsistenan tertinggi. Hal tersebut dapat dilihat pada Tabel II, modulasi 50\% memiliki tingkat kekonsistenan 5 yang mengartikan bahwa modulasi $50 \%$ memiliki nilai ragam residu intensitas terkecil pada setiap ulangan dibandingkan dengan modulasi lainnya. Setelah didapatkan modulasi yang konsisten, modulasi tersebut diharapkan memiliki residu intensitas yang konstan. Oleh sebab itu dilakukan uji nilai tengah menggunakan analisis ragam.

Berdasarkan hasil analisis, tiga modulasi yang konsisten juga merupakan modulasi yang konstan karena hasil uji nilai tengah memberikan kesimpulan menerima Ho yang berarti bahwa nilai tengah modulasi untuk setiap ulangan sama. Selain merupakan modulasi yang memiliki tingkat kekonsistenan yang tinggi, modulasi $50 \%$ juga merupakan modulasi yang konstan. Hal tersebut ditunjukan oleh Tabel III yang memberikan kesimpulan menerima Ho dari hasil uji nilai tengah

Selain merupakan modulasi yang konsisten dan konstan. Modulasi 50\% merupakan modulasi yang memiliki tingkat residu intensitas yang rendah. Hal ini ditunjukan secara eksploratif pada Gambar 3, Gambar 4, dan Gambar 5 yang diberi tanda lingkaran merah. Oleh sebab itu dapat disimpulkan bahwa modulasi 50\% merupakan modulasi terbaik.

\section{Statistical Process Control (Bagan Kendali Mutu Individual Moving Range)}

Analisis bagan kendali mutu Individual Moving Range dalam penelitian ini digunakan untuk mengetahui kestabilan atau keterkendalian proses dari residu intensitas modulasi 50\% untuk masingmasing responden yang memliki kadar glukosa darah $67 \mathrm{mg} / \mathrm{dL}, 123 \mathrm{mg} / \mathrm{dL}$, dan $276 \mathrm{mg} / \mathrm{dL}$. Hasil dari bagan kendali ini akan menjadi masukan untuk perbaikan alat pada produksi alat selanjutnya. Nelson Rules digunakan pada penelitian ini sebagai ukuran sensitifitas untuk menentukan apakah proses dari residu intensitas modulasi $50 \%$ sudah stabil atau belum.

Gambar 6 sampai dengan Gambar 11 merupakan bagan kendali mutu Moving Range dan Individual untuk responden yang terpilih berdasarkan kategori diabetes. Berdasarkan penjelasan sebelumnya, bagan kendali mutu Individual Moving Range menggunakan Nelson Rules sebagai ukuran sensitifitas. Penelitian ini memodifikasinya dengan menggunakan tiga kombinasi standar deviasi untuk batas pengendali atas dan batas pengendali bawah. Tiga kombinasi standar deviasi tersebut yaitu 1 standar deviasi, 2 standar deviasi, dan 3 standar deviasi.

Gambar 6 dan Gambar 7 menunjukan semua amatan terkendali ketika menggunakan 2 dan 3 standar deviasi sebagai batas pengendalinya. Hal ini 
Tabel II

NILAI RAGAM MODULASI 50\% UNTUK MASING-MASING PUNCAK PADA KADAR GLUKOSA DARAH 67 MG/DL, 123 MG/DL, DAN 276 $\mathrm{MG} / \mathrm{DL}$

\begin{tabular}{lcccccc}
\hline & \multicolumn{2}{c}{$67 \mathrm{mg} / \mathrm{dL}$} & \multicolumn{2}{c}{$123 \mathrm{mg} / \mathrm{dL}$} & \multicolumn{2}{c}{$276 \mathrm{mg} / \mathrm{dL}$} \\
\hline & Puncak & Puncak & Puncak & Puncak & Puncak & Puncak \\
& 1 & 2 & 1 & 2 & 1 & 2 \\
\hline Ulangan 1 & 34778 & 29043 & 12521 & 21733 & 43534 & 120057 \\
Ulangan 2 & 32423 & 41821 & 17566 & 12272 & 47031 & 195436 \\
Ulangan 3 & 31034 & 35157 & 19466 & 23737 & 42201 & 23071 \\
Ulangan 4 & 8517 & 56373 & 13372 & 16162 & 75519 & 34304 \\
Ulangan 5 & 28983 & 27905 & 16235 & 15329 & 20964 & 115332 \\
\hline Max & 8517 & 27905 & 12521 & 12272 & 20964 & 23071 \\
Min & 34778 & 56373 & 19466 & 23737 & 75519 & 195436 \\
Rata-Rata & 27147 & 38060 & 15832 & 174847 & 45850 & 97640 \\
Kekonsistenan & 5 & 5 & 5 & 5 & 5 & 5 \\
Penyimpangan & 7631 & 18313 & 3634 & 5891 & 29669 & 97796 \\
\hline
\end{tabular}

Tabel III

HASIL UJI NILAI TENGAH MODULASI 50\% UNTUK MASING-MASING PUNCAK PADA KADAR GLUKOSA DARAH 67 MG/DL, 123 MG/DL, DAN $276 \mathrm{MG} / \mathrm{DL}$

\begin{tabular}{lcccccc}
\hline & \multicolumn{2}{c}{$67 \mathrm{mg} / \mathrm{dL}$} & \multicolumn{2}{c}{$123 \mathrm{mg} / \mathrm{dL}$} & \multicolumn{2}{c}{$276 \mathrm{mg} / \mathrm{dL}$} \\
\hline & Puncak & Puncak & Puncak & Puncak & Puncak & Puncak \\
& 1 & 2 & 1 & 2 & 1 & 2 \\
\hline Ulangan 1 & 948 & 924 & 517 & 563 & 1078 & 986 \\
Ulangan 2 & 1053 & 1006 & 579 & 584 & 1108 & 991 \\
Ulangan 3 & 993 & 939 & 507 & 479 & 985 & 996 \\
Ulangan 4 & 748 & 925 & 537 & 513 & 898 & 1033 \\
Ulangan 5 & 881 & 873 & 535 & 544 & 1176 & 983 \\
\hline Max & 748 & 873 & 507 & 479 & 898 & 983 \\
Min & 1053 & 1006 & 579 & 584 & 1176 & 1033 \\
Rata-Rata & 913 & 933 & 535 & 537 & 1049 & 998 \\
Hasil & Terima & Terima & Terima & Terima & Terima & Terima \\
Pengujian & Ho & Ho & Ho & Ho & Ho & Ho \\
\hline
\end{tabular}

dibuktikan karena tidak ada amatan yang keluar dari batas pengendali atas maupun bawah. Hal tersebut berbeda jika menggunakan 1 standar deviasi karena terdapat beberapa amatan yang keluar dari batas pengendali bawah dan atas. Gambar 8 dan Gambar 9 juga menunjukan beberapa amatan keluar dari batas pengendali bawah dan atas jika menggunakan 1 standar deviasi sebagai batas pengendalinya. Gambar 6 dan Gambar 8 yang menampilkan ukuran penyebaran tidak menunjukan ketidakterkendalian ketika menggunakan 1 standar deviasi sebagai batas kendali. Hal tersebut juga ditunjukan oleh Gambar 7 dan Gambar 9 yang menampilkan ukuran pemusatan. Oleh sebab itu dapat disimpulkan bahwa ketika menggunakan 1 standar deviasi sebagai batas pengendali, bagan kendali mutu Individual Moving Range dari alat pengukur kadar glukosa darah noninvasif pada responden dengan kadar glukosa 67 mg/dL dan 123 mg/dL tidak menunjukan kestabilan.

Gambar 10 menunjukan semua amatan terkendali ketika menggunakan 3 standar deviasi sebagai batas pengendalinya. Hal ini dibuktikan karena tidak ada amatan yang keluar dari batas pengendali atas maupun bawah. Hal tersebut berbeda jika menggunakan 1 dan 2 standar deviasi karena terdapat beberapa amatan yang keluar dari batas pengendali bawah dan atas. Gambar 11 juga menunjukan beberapa amatan keluar dari batas pengendali bawah dan atas jika menggunakan 1 dan 2 standar deviasi sebagai 
Tabel IV

NILAI $\sigma$ DAN $\bar{x}$ DARI HASIL PEMERIKSAAN KESTABILAN MENGGUNAKAN BAGAN KENDALI MUTU INDIVIDUAL Moving Range

\begin{tabular}{lcccccccc}
\hline & \multicolumn{2}{c}{$68 \mathrm{mg} / \mathrm{dL}$} & \multicolumn{2}{c}{$87 \mathrm{mg} / \mathrm{dL}$} & \multicolumn{2}{c}{$70 \mathrm{mg} / \mathrm{dL}$} & \multicolumn{2}{c}{$76 \mathrm{mg} / \mathrm{dL}$} \\
\hline & $\sigma$ & $\bar{x}$ & $\sigma$ & $\bar{x}$ & $\sigma$ & $\bar{x}$ & $\sigma$ & $\bar{x}$ \\
\hline Responden 1 & $2 \sigma$ & 739 & $3 \sigma$ & 775.5 & $3 \sigma$ & 497.4 & $3 \sigma$ & 1134.6 \\
Responden 2 & $2 \sigma$ & 622 & $2 \sigma$ & 1099 & $3 \sigma$ & 543.4 & $3 \sigma$ & 5380 \\
Responden 3 & & & $2 \sigma$ & 785 & $3 \sigma$ & 923 & $3 \sigma$ & 536.9 \\
Responden 4 & & & & & $2 \sigma$ & 939 & $3 \sigma$ & 490.1 \\
Responden 5 & & & & & & & $2 \sigma$ & 571 \\
\hline
\end{tabular}

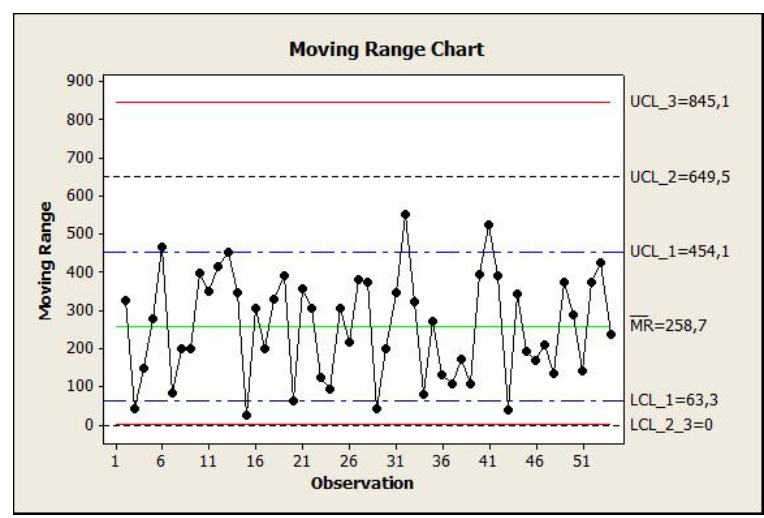

Gambar 6. Bagan kendali mutu Moving Range hasil keluaran alat non-invasif untuk kadar glukosa darah $67 \mathrm{mg} / \mathrm{dL}$

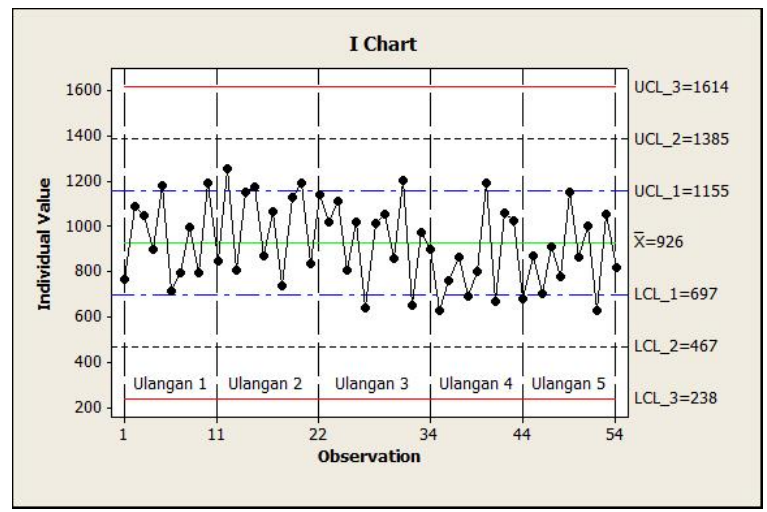

Gambar 7. Bagan kendali mutu Individual hasil keluaran alat noninvasif untuk kadar glukosa darah $67 \mathrm{mg} / \mathrm{dL}$

batas pengendalinya. Gambar 10 dan Gambar 11 yang masing-masing menampilkan ukuran penyebaran dan pemusatan tidak menunjukan ketidakterkendalian ketika menggunakan 1 dan 2 standar deviasi sebagai batas kendali. Selain itu adanya amatan di luar batas pengendali, bagan kendali Individual (Gambar 11) memiliki 15 titik dalam satu baris dengan nilai 1 standar deviasi dari garis pusat yang

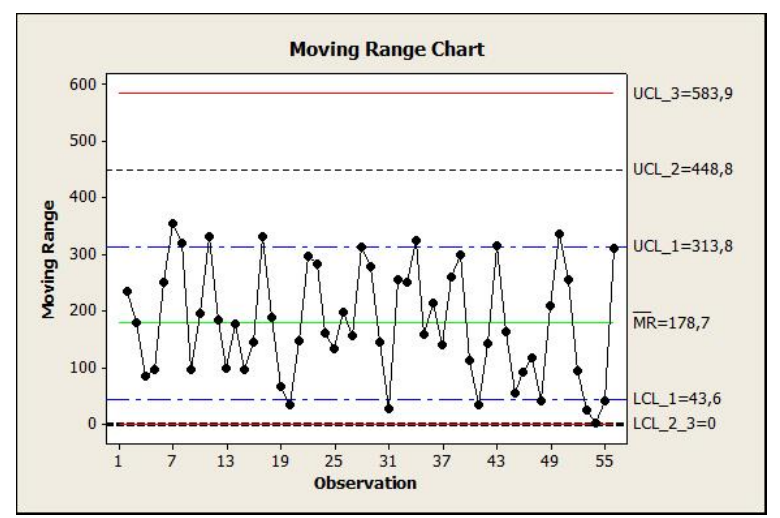

Gambar 8. Bagan kendali mutu Moving Range hasil keluaran alat non-invasif untuk kadar glukosa darah $123 \mathrm{mg} / \mathrm{dL}$

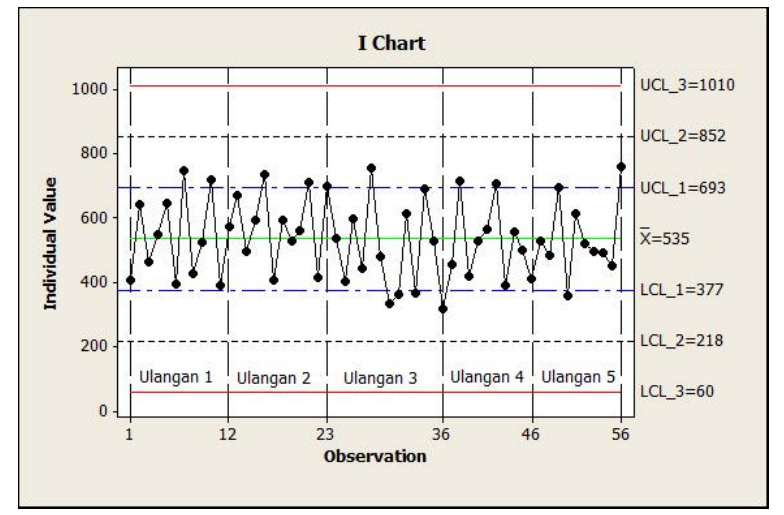

Gambar 9. Bagan kendali mutu Individual hasil keluaran alat noninvasif untuk kadar glukosa darah $123 \mathrm{mg} / \mathrm{dL}$

mengindikasikan ketidakstabilan proses. Oleh sebab itu dapat disimpulkan bahwa ketika menggunakan 1 dan 2 standar deviasi sebagai batas pengendali, bagan kendali mutu Individual Moving Range dari alat pengukur kadar glukosa darah non-invasif pada responden dengan kadar glukosa $276 \mathrm{mg} / \mathrm{dL}$ tidak menunjukan kestabilan.

Pemeriksaan selanjutnya dilakukan terhadap be- 


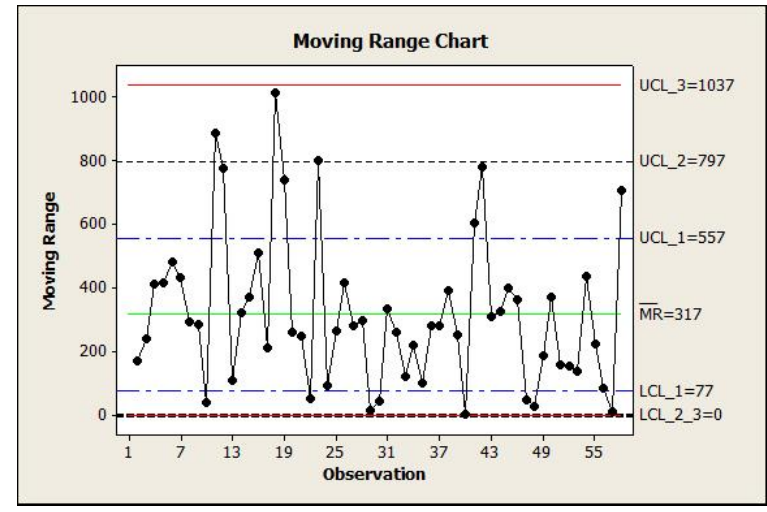

Gambar 10. Bagan kendali mutu Moving Range hasil keluaran alat non-invasif untuk kadar glukosa darah $276 \mathrm{mg} / \mathrm{dL}$

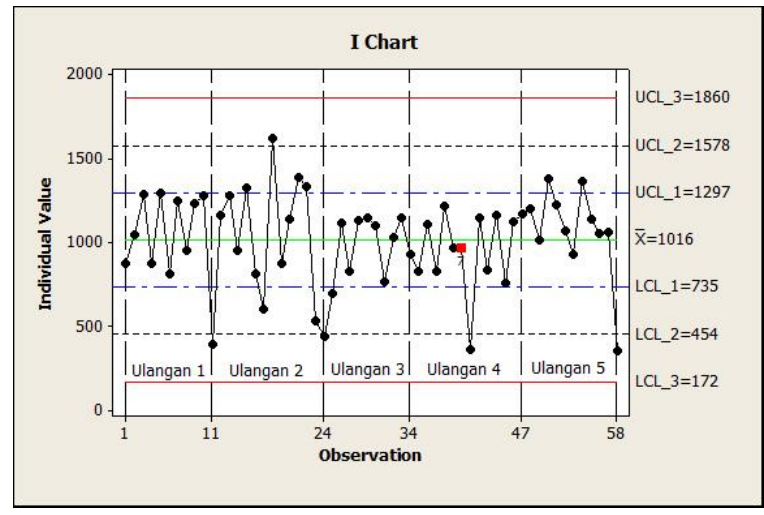

Gambar 11. Bagan kendali mutu Individual hasil keluaran alat noninvasif untuk kadar glukosa darah $276 \mathrm{mg} / \mathrm{dL}$

berapa responden yang memiliki kadar glukosa darah $68 \mathrm{mg} / \mathrm{dL}, 87 \mathrm{mg} / \mathrm{dL}, 70 \mathrm{mg} / \mathrm{dL}$, dan 76 $\mathrm{mg} / \mathrm{dL}$. Berdasarkan penjelasan pada Tabel IV, pemeriksaan kestabilan proses pada alat ketika menangkap residu intensitas menunjukan kestabilan jika menggunakan $2 \sigma$ dan $3 \sigma$. Oleh sebab itu, jika alat pengukur kadar glukosa darah non-invasif ingin menunjukan kestabilan sebaiknya menggunakan 3 $\sigma$. Kestabilan tersebut terjadi pada setiap responden yang terpilih. Berbeda halnya jika membandingkan beberapa responden yang memiliki kadar glukosa darah yang sama. Keragaman yang terjadi masih cukup tinggi jika membandingkan beberapa responden yang memiliki kadar glukosa darah yang sama. Hal tersebut dapat menjadi saran dan masukan untuk penelitian dan pengembangan alat selanjutnya.

\section{SIMPULAN DAN SARAN}

\section{A. Simpulan}

Analisis statistical process control menggunakan bagan kendali mutu Individual Moving Range mengindikasikan kestabilan proses pada masingmasing responden. Namun demikian, antar responden yang satu dengan responden yang lainnya memiliki proses yang belum stabil meskipun kadar glukosa darah yang dimiliki oleh responden tersebut sama. Hal tersebut dapat dilihat dari residu intensitas yang ditangkap oleh alat memiliki ragam yang tidak minimum dan presisinya masih rendah. Oleh sebab itu dapat disimpulkan bahwa alat pengukur kadar glukosa darah non-invasif belum menunjukan kestabilan proses untuk menangkap residu intensitas

\section{B. Saran}

Penelitian dan pengembangan alat pengukur kadar glukosa darah non-invasif selanjutnya perlu dilakukan perbaikan agar lebih dapat menunjukan kestabilan proses untuk menangkap residu intensitas. Selain itu, penelitian selanjutnya dapat menggunakan hanya satu modulasi yaitu modulasi $50 \%$ yang merupakan modulasi terbaik.

\section{DAFTAR PUSTAKa}

ADA (2014). Diagnosis and classification of diabetes mellitus. Diabetes Care 37(s1), 81-90.

Maslow, A. (1984). Motivation and Personality. Jakarta (ID): Pustaka Binaman Pressindo.

Montgomerry, D. (2009). Introduction to Statistical Quality Control Sixth Edition. New York (US): John Wiley and Sons, Inc.

Stuart, B. (2004). Infrared Spectroscopy: Fundamentals and Applications. Sydney (AU): John Wiley and Sons, Ltd.

Wild, S., G. Roglic, A. Green, R. Sicree, and H. King (2004). Gobal prevalence of diabetes estimates for the year 2000 and projections for 2030. Diabetes Care 27(5), 1053-1074. 